\title{
ESCOLARIZAÇÃO DA SEXUALIDADE: O SILÊNCIO COMO PRÁTICA PEDAGÓGICA DA EDUCAÇÃO FÍSICA
}

\author{
SEXUALITY SCHOOLING: SILENCE AS A PEDAGOGICAL PRACTICE IN \\ PHYSICAL EDUCATION
}

\author{
EDUCACIÓN DE LA SEXUALIDAD: EL SILENCIO COMO PRÁCTICA \\ PEDAGÓGICA DE LA EDUCACIÓN FÍSICA
}

\author{
Aline Silva Nicolino*, Marlucy Alves Paraíso**
}

\section{Palavras chave:}

Ensino.

Sexualidade.

Educação Física.

Dissertações

acadêmicas.

\begin{abstract}
Resumo: $O$ estudo investiga os saberes produzidos sobre a escolarização da sexualidade em teses e dissertações desenvolvidas na área da Educação Física brasileira. Trata-se de identificar o que a área vem produzindo sobre o tema e os efeitos desses saberes no contexto escolar. Para isso, foram lidas todas as produções da área que tratam sobre a sexualidade na escola, concluídas até 0 ano de 2014. O argumento desenvolvido é o de que a Educação Física entra no contexto escolar pela lógica biológica, valendo-se da ideia de corpo "saudável" para justificar uma educação heteronormativa.A análise mostra que o "não-dito" é uma estratégia eficiente para ensinar sobre a sexualidade, constituindo-se, também, em uma prática pedagógica.
\end{abstract}

Abstract: The study investigates knowledge produced in theses and dissertations about schooling of sexuality in the area of the Physical Education in Brazil. It identifies what the area has produced on the subject and its effects on the school context. All productions on sexuality at school finished by 2014 were read. The argument developed holds that Physical Education is included in the school context through a biological logic, using the idea of the "healthy" body to justify heteronormative education. The analysis shows that the "unsaid" is an effective strategy for teaching about sexuality, being also a pedagogical practice.

Resumen: El estudio investiga el conocimiento producido sobre la escolarización de la sexualidad en tesis y disertaciones desarrolladas en el área de la Educación Física brasileña. Identifica lo que el área ha producido sobre el tema y los efectos de ese conocimiento en el contexto escolar. Para ello, fueron leídas todas las producciones del área que tratan sobre la sexualidad en la escuela hasta el año 2014. El argumento desarrollado es que la Educación Física entra en el contexto escolar por medio de la lógica biológica, haciendo uso de la idea de cuerpo "sano" para justificar una educación heteronormativa. El análisis muestra que lo "no dicho" es una estrategia eficaz para enseñar sobre la sexualidad, constituyéndose también una práctica pedagógica.
*Universidade Federal de Goiás. Goiânia, GO, Brasil.

E-mail:aline.nicolino@gmail.com

**Universidade Federal de Minas Gerais. Belo Horizonte, MG, Brasil. E-mail: marlucyparaiso@gmail.com

Recebido em: 21-03-2017 Aprovado em: 11-11-2017

DOI: http://dx.doi.org/10.22456/1982-8918.72058

\section{(c) (1) (8) Licence}




\section{INTRODUÇÃOO}

Há temposa sexualidade vem sendo ensinada nas escolas brasileiras. Esforços despendidos em sistematizar esse saber podem ser observados em produções nas áreas da Educação e da Saúde. No campo educacional, um dos efeitos desse saber pode ser observado na ideia de normalidade, guiada por uma matriz heterossexual, produzida por uma intervenção pedagógica "apropriada", que coloca a sexualidade como centro de preocupação moral do discurso pedagógico (BRITZMAN, 2001). No campo da saúde, alguns dos efeitos desse saber operam tanto para uma responsabilização individual, quanto para a epidemiologia do risco, mobilizados pelo advento da aids (LEÃO; RIBEIRO, 2012; CÉSAR, 2009; MONTEIRO, 2002). Educar a sexualidade por meio de saberes sobre o funcionamento biológico do corpo constituiu uma das estratégias mais utilizadas pelo meio científico para instituir uma "ciência do sexo". As estratégias de interpelação e reiteração que mobilizam a produção de tais saberes estão, portanto, atravessadas pelo movimento higienistasocial que vislumbra na educação sexual escolar uma possibilidade de intervenção do Estado na saúde e na educação da população (BRITZMAN, 2001). Estratégia aqui entendida como um conjunto de "[...] mecanismos utilizados nas relações de poder, que visam alcançar seus objetivos" (CASTRO, 2009, p.151), neste caso, os meios empregados para produzir corpos "saudáveis".

Uma aliada desse movimento de educar a sexualidade na escola éa Educação Física. Responsável pela tarefa de produzir a "normalização" dos corpos, a Educação Física divulgou a sexualidade como um produto moral, oficializando a prática heterossexualcomo norma hegemônica das relações humanas (ALTMANN, 1998; 2001; GOELLNER, 2003; ROMERO, 1994; SOARES, 2001).A normalização é o processo por meio do qual normas de gênero nomeiam o corpo como feminino ou masculino, tendo por referência a heterossexualidade como matriz para delimitar o sujeito como legítimo. Essa legitimidade éatribuída pela reiteração de como cada um(a) deve se comportar, agir e pensar, supondo "[...] o sexo como um 'dado' anterior à cultura, de caráter imutável, a-histórico e binário" (LOURO, 2008, p. 15).Para esse processo de normalização, a Educação Física valeu-se do discurso médico higienista e obteve reconhecimento acadêmico ao ensinar que o disciplinamento do caráter e a higiene do corpo se constituem por meio de uma educação moral, física e intelectual heterossexual, transmitindo a ideia de família nuclear como a mais adequada.A Educação Física,nesse sentido,associou uma educação saudável à prevenção e à profilaxia, disseminando a ideia de um corpo forte, resistente e adequado aos parâmetros de produtividade (CASTELLANI FILHO, 1988; FRAGA, 2006; GOELLNER, 2009). Assim, um conjunto de medidas profiláticas que objetivavam conformar, definir e propor um determinado estilo de vida saudável (heterossexual, familiar e reprodutivo) foi ensinado em práticas escolares, especialmente na primeira metade do século $X X$ no Brasil, paragarantir a manutenção da ordem social (GOELLNER, 2003; GÓIS JUNIOR; LOVISOLO, 2003; SOARES, 2000; 2001). A Educação Física entra, portanto, no contexto escolar pela lógica biológica, em que o corpo é educado nas ideias de hierarquia, ordem, disciplina, higiene e esforço individual (SOARES, 2001), guiada, sobretudo, por uma racionalidade moral do sexo.

Essa racionalidade guiada por uma moral higiênica sobre o corpo constitui os primeiros conteúdos pedagógicos da Educação Física na escola. O que significa dizer que a 
sexualidade é um dos instrumentos utilizados pela Educação Física para reiterar e produzir a ideia de uma moral sexual do corpo social, pautando-se na heterossexualidade como norma para a produção de sujeitos "saudáveis e normais". Portanto, o argumento desenvolvido é o de que a Educação Física entra no contexto escolar pela lógica biológica, valendo-se das ideias de saúde física e moral para educar os corpos escolares por meio da heteronormatividade. Um dos efeitos dessa divisão pode ser identificado no maior reconhecimento da discussão da sexualidade na escola em saberes que atestam uma determinada "natureza" do homem e da mulher, constituído por uma base universal, e, portanto, de difícil questionamento (LOURO, 1997). Por isso, os saberes que constituem a discussão da sexualidade na escola são, nesse sentido, entendidos como um dos eixos centrais para se pensar a educação do corpo na Educação Física. Fazendo-se necessário investigar o quê, como e quais os efeitos dos saberes e dos conhecimentos produzidos sobre esse processo de escolarização da sexualidade em teses e dissertações brasileiras na área da Educação Física, procurase conhecer quais os interesses e as demandas que fomentaram esses trabalhos, quais saberes estão sendo apresentados como "verdadeiros" para tratar o tema e quais os efeitos disso na Educação Física.

Para fazer essa análise, investigamos os modos através dos quais os saberes sobre a sexualidade são introduzidos e modificados no meio escolar. Para isso, trazemos a compreensãode saber relacionado a um conjunto de ideias, de estruturas de pensamento e de práticas sociais que circulam nos espaços educacionais investigados e que dizem respeito à sexualidade. Compreendemos saberes como elementos, conceitos e estruturas, os quais são sempre relativos e formados por práticas discursivas e que são indispensáveis à constituição de uma ciência (FOUCAULT, 2007). Nesse sentido, o saber a que se faz referência diz respeito às "verdades" atribuídas à sexualidade no contexto escolar, com base nas produções acadêmicas desenvolvidas na área da Educação Física.

Para analisar a forma como se dá a produção desses saberes, é preciso apresentarque a sexualidade é entendida como uma questão política, que merece ser investigada e analisada de modo histórico e sociológico, como descreve Jeffrey Weeks (2001). A discussão da sexualidade na escola envolve "[...] conhecimentos e práticas sociais voltadas ao cuidado com o corpo, a uma vivência consciente e prazerosa da sexualidade [...]" (UNBEHAUM; CAVASIN; GAVA, 2010, p. 9), para além dos discursos de prevenção e medicalização do corpo. Trata-se, então, de identificar as demandas apresentadas pela escola, os saberes acionados para tratar o tema e o que se constituiu como conhecimento escolar. Ao exercício intencional e repetitivo de saberes sobre a sexualidade no contexto escolar, constituído por uma seleção de valores e normas educacionais operando em uma rede de linguagens, discursos e práticas, denominamos de escolarização da sexualidade. Isto é, para escolarizar a sexualidade é preciso "torná-la um tema ensinável na escola e, isso, não se dá de forma simétrica e sem disputas, mas em meio a conflitos e relações de poder" (NICOLINO; PARAÍSO, 2014, p. 173), em um exercício constante de reforçonos modos de pensar, compreender e agir.

Nesse sentido, é possível identificar que a sexualidade vem sendo ensinada há anos na escola e que houve a contribuição da Educação Física, por meio de diferentes linguagens para educar esses corpos (ROMERO, 1994; FRAGA, 2000; ALTMANN, 2001; 2006; DORNELLES, 2007; 2013a). Entretanto, análises que sistematizam os saberes, as 
estratégias e os efeitos produzidos sobre o tema na área ainda são pouco explorados. 0 que significa dizer que trazer a sexualidade como objeto de investigação, por meio de um levantamento sobre o que se transformou em conhecimento acadêmico, visa dar visibilidade aos mecanismos utilizados pela Educação Física para tratar o tema e, nesse sentido, trazer as relações de poder que constituem a discussão na escola. Significa dizer, também, que mapear os saberes que compõem a discussão da sexualidade no contexto escolar e analisar seus efeitos na produção acadêmica da Educação Física é uma ação que ainda não foi realizada, e, por isso, constitui o esforço investigativo deste estudo.

\section{METODOLOGIA}

Para analisar esse processo de escolarização dos saberes referentes à sexualidade recorremos às produções desenvolvidas nos 52 cursos de mestrado e doutorado em Educação Física no Brasil, mantidos por 32 universidades públicas e particulares. Para realizar o levantamento utilizamos as expressões: escolarização da sexualidade, sexualidade, educação sexual, orientação sexual e/ou escola, e estabelecemos como critério de inclusão ter sido pensado e/ou realizado no contexto escolar e concluído até o ano de 2014. Ao todo, foram analisadas seis produções, sendo cinco dissertações e uma tese.

Após sistematizar as informações, organizamos a escrita em três partes. A primeira, nomeada "Caminhos percorridos: breve descrição do mapeamento das dissertações e teses produzidas na Educação Física", mapeia os locais e as pessoas que produziram os trabalhos, assim como os temas que atravessam a discussão da sexualidade na área. A segunda parte, intitulada "O não-dito da sexualidade: a ausência como estratégia de produção dos corpos escolares", apresenta o silêncio pedagógico sobre a discussão da sexualidade na escola como uma estratégia eficiente de ensinar como os corpos escolares devem se comportar para serem "normais e saudáveis". A terceira e última parte, nomeada "O que o silêncio ensina na Educação Física?", traz os efeitos produzidos pelo silenciamento pedagógico, no sentido de identificar quais saberes foram incorporados às práticas escolares, por meio do que vem sendo produzido como "verdade" na discussão da sexualidade na Educação Física.

\section{CAMINHOS PERCORRIDOS: BREVE DESCRIÇÃO DO MAPEAMENTO DAS DISSERTAÇÕES E TESES PRODUZIDAS NA EDUCAÇÃO FÍSICA}

Ao mapearmos a produção da Educação Física sobre a sexualidade no contexto escolar, verificamos que a Região Sul do país concentra o maior número de produções sobre o tema na área da Educação Física, apresentando um total de quatro trabalhos. O estado do Rio Grande do Sul com dois trabalhos concluídos na capital gaúcha, seguido do estado de Santa Catarina, com dois estudos realizados em Florianópolis. Logo em seguida, a Região Sudeste com dois trabalhos, os quais foram desenvolvidos no estado de São Paulo, nas cidades de Rio Claro e São Carlos. Todos os trabalhos selecionados para esta análise foram realizados em instituições públicas, entre os anos de 2005 e 2013, período em que foram encontradas produções sobre o tema na área. 
Quadro 1 - Sistematização das informações referentes às dissertações e tese produzidas nos programas de pós-graduação em Educação Física sobre a sexualidade no contexto escolar

\begin{tabular}{|c|c|c|c|c|c|c|}
\hline Instituição & UF & Programa & Curso & Ano & Pesquisador(a) & Título do trabalho \\
\hline \multirow{2}{*}{ UFRGS } & \multirow{2}{*}{$\mathrm{RS}$} & \multirow{2}{*}{$\begin{array}{l}\text { Ciências do } \\
\text { Movimento } \\
\text { Humano }\end{array}$} & Mestrado & 2005 & Ileana Wenetz & $\begin{array}{c}\text { Gênero e sexualidade nas } \\
\text { brincadeiras do recreio }\end{array}$ \\
\hline & & & Doutorado & 2012 & Ileana Wenetz & $\begin{array}{l}\text { Brincadeiras de crianças: corpos } \\
\text { marcados pelo gênero e pela } \\
\text { sexualidade }\end{array}$ \\
\hline \multirow{2}{*}{ UFSC } & \multirow{2}{*}{ SC } & \multirow{2}{*}{$\begin{array}{l}\text { Educação } \\
\text { Física }\end{array}$} & Mestrado & 2008 & $\begin{array}{l}\text { Luciene Neves } \\
\text { Santos }\end{array}$ & $\begin{array}{l}\text { Corpo, gênero e sexualidade: } \\
\text { educar meninas e meninos para } \\
\text { além da homofobia }\end{array}$ \\
\hline & & & Mestrado & 2013 & $\begin{array}{l}\text { Julia Mara P. } \\
\text { Silvestrin }\end{array}$ & $\begin{array}{l}\text { Perform(atividade) na escola: } \\
\text { reflexões sobre gênero na } \\
\text { Educação Física }\end{array}$ \\
\hline UNESP/RC & \multirow{2}{*}{ SP } & $\begin{array}{l}\text { Ciências da } \\
\text { Motricidade }\end{array}$ & Mestrado & 2009 & $\begin{array}{l}\text { Ivan Luís dos } \\
\text { Santos }\end{array}$ & $\begin{array}{l}\text { A "orientação sexual" e a } \\
\text { Educação Física: sobre a prática } \\
\text { pedagógica do professor na } \\
\text { escola }\end{array}$ \\
\hline UFSCAR & & $\begin{array}{c}\text { Terapia } \\
\text { Ocupacional* }^{*}\end{array}$ & Mestrado & 2012 & Sara Caram Sfair & $\begin{array}{c}\text { Educação Sexual para } \\
\text { adolescentes e jovens: o que } \\
\text { preveem os documentos públicos } \\
\text { nos níveis federal e estadual em } \\
\text { São Paulo }\end{array}$ \\
\hline
\end{tabular}

* Segundo os critérios estabelecidos pela Capes, o programa de Terapia Ocupacional encontra-se na área da Educação Física. Fonte: Das autoras.

Ao lermos os títulos dos trabalhos é possível dizer que os termos "gênero" e "corpo" representam a maior parte $(66,7 \%)$ das discussões sobre a sexualidade no contexto escolar (WENETZ, 2005; 2012; SILVESTRIN, 2013; SANTOS, 2008). Somente em dois trabalhos os termos "gênero" e "corpo" não aparecem no título (SANTOS, 2009; SFAIR, 2012).Esses trabalhos são os únicos que anunciam no título, no resumo e nas palavras-chave tratar somente da sexualidade. Termo este que é substituído pelas expressões orientação sexual e educação sexual.O que significa dizer que há distinção nas definições no campo acadêmico para tratar o tema, em virtude de disputas políticas do campo da sexologia educacional, que busca reconhecimento científico no contexto educacional.

Atentas a isso, identificamos que as diversas demandas e singularidades que constituem a discussão da sexualidade na área estão subsumidas à questão da heterossexualidade. Para apresentar o modo como isso se dá em cada contexto investigado, as(os) pesquisadoras(es) se valem de diversos mecanismos, como o uso de termos e conceitos, para apresentar os discursos que regem as "verdades"sobre o tema. Esses meios se dão fundamentalmente pelo silenciamento pedagógico que produz modos de aprendizagem de "como ser feminina" e de "como ser masculino". Esse processo de educar os corpos denominamos de escolarização da sexualidade, e os meios utilizados para isso nomeamos de estratégia. Essa leitura sobre os trabalhos nos permitiu identificar que há diversas estratégias de reiteração sendo acionadas no contexto escolar para produzir a heterossexualidade como norma educativa. Estratégias que ora são identificadas pelo silêncio pedagógico (WENETZ, 2005; 2012; SANTOS, 2008; 2009; SFAIR, 2012; SILVESTRIN, 2013); ora pela ausência do uso de determinados termos e saberes, em documentos oficiais que regem o currículo da Educação Física Escolar (SANTOS, 
2009; SFAIR, 2012); ora por saberes individuais pautados em uma moral religiosa (SANTOS, 2008; SILVESTRIN, 2013; SANTOS, 2009); ora pelo discurso biologicista para reiterar a lógica heteronormativa na escola (WENETZ, 2005; 2012; SANTOS, 2008; SILVESTRIN, 2013; SFAIR, 2012). O silêncio pedagógicofoi a estratégia que mais nos chamou a atenção, por estar presente em todos os trabalhos e por se mostrar uma estratégia eficiente para desqualificar saberes periféricos, invisibilizar grupos e, sobretudo, não reconhecer as diferenças que os constituem.

De modo geral, esse primeiro levantamento nos permitiu identificar que "gênero" e "corpo" são os termos de maior representação na discussão sobre a sexualidade na Educação Física. Identificamos, também, que a produção sobre o temana área é incipiente, masque são as mulheres, em sua maior parte, que vêm produzindo a discussão de sexualidade na Educação Física Escolar, marcando politicamente a escrita científica desse campo. Entendemos, portanto, que os termos escolhidos para estarem nos títulos, nas palavras-chave e nos resumos não são neutros, constituem as "verdades" mais representativas dessa discussãoe, por isso, merecem ser analisados.

\section{0 "NÃO-DITO" DA SEXUALIDADE: O SILÊNCIO COMO ESTRATÉGIA DE PRODUÇÃO DOS CORPOS ESCOLARES}

Chama atenção nos trabalhos analisados não apenas a frequência com que 0 termo "gênero" aparece, mas, sobretudo, como o tema atravessa e constitui a discussão da sexualidade. 0 conceito de gênero é utilizado para apresentar como se dá o processo de escolarização dos corpos de meninos e meninas dentro e fora das aulas de Educação Física. Os trabalhos, nesse sentido, anunciam o quanto o sexo biológico marca a constituição dos corpos escolares, denunciando o quanto as diferenças anatômicas dos corpos são utilizadas para justificar a produção das desigualdades no contexto escolar. As relações de gênero são reguladas por uma lógica generificada, em que a mulher é representada como feminina e detentora de uma vagina e o homem como masculino e detentor de um pênis. Segundo os estudos, esses ensinamentos se dão, sobretudo, pelo "não-dito" produzido pelas e nas práticas pedagógicas, dentro e fora das aulas de Educação Física.

O silenciamento perante os conflitos que envolvem o tema na escola são identificados com preocupação, por parte de algumas pesquisadoras (WENETZ, 2005; 2012; SANTOS, 2008; SILVESTRIN, 2013), por ensinar que há uma sexualidade representando a verdade sobre os corpos. Preocupação anunciada nos trabalhos como o "silêncio de uma sexualidade única". Operando com essa lógica para analisar as práticas pedagógicas, os trabalhos mostram que a não intervenção em práticas cotidianas na escola, que buscam ofender e desvalorizar tudo o que escapa à norma heterossexual, diz, sem dizer, o que pode e o que não pode ser considerado como "normal". Silvestrin (2013) descreve ter chegado à mesma conclusão apresentada no trabalho de Santos (2008), ao constatar que docentes acabam reforçando a norma e os estereótipos sexuais e de gênero, pelo silenciamento, ao afirmarem que não sabem "[...] como lidar com os embates sexistas e homofóbicos travados cotidianamente na Educação Física Escolar" (SILVESTRIN, 2013, p. 92), por falta de formação.

O silenciamento permite, nesse sentido, conformar à lógica, naturalizando-a. O que significa dizer que as(os) docentes, ao justificarem a falta de ação pedagógica, por não perceberem os conflitos e as questões que envolvem a sexualidade, estão impossibilitando 
enfrentamentos, questionamentos e diálogos sobre as experiências produzidas nos e entre os corpos. Por isso, a ideia de desconhecer, como dito por um professor, ao comentar que não percebe tais questões em suas aulas ("como a gente não sabe como fazer, como sair disso, se deixa, [...] aí se aparecer na sua turma apareceu, se não apareceu melhor ainda [...]"), é analisada como perniciosa ao trato pedagógico (SANTOS, 2008, p. 101). Os trabalhos trazem, portanto, que a falta de ação docente produz uma ação pedagógica, o consentimento.

Com base nessa lógica de estabelecer corpos generificados em feminino e masculino para pensar a educação dos corpos, o futebol é apresentado nos trabalhos como um forte representante desse processo educativo, ao marcar no corpo as referências de masculinidades que precisam operar. Marcas que podem ser observadas na fala de uma professora ao trazer

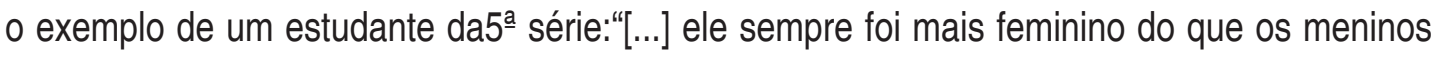
e fazia questão de mostrar isso também, então os meninos xingavam mesmo e gozavam e riam, não queriam deixar jogar futebol" (SANTOS, 2008, p. 99). A prática de futebol tem um lugar quase que simbólico no contexto escolar, especialmente, dentro das aulas de Educação Física, como observa a pesquisadora: "A prática do futebol parece ser colocada aí quase como uma obrigação para um menino que pretende ser heterossexual; do contrário, poderá ser classificado como desviante" (WENETZ, 2012, p. 162). 0 deboche e a ridicularização têm 0 efeito de acusação para quem transgride as fronteiras de gênero, recebendo "[...] a risada, o deboche e o apelido, como mecanismos de afastar os meninos do que não devem fazer parte: a homossexualidade" (WENETZ, 2012, p. 153).

A dança, nesse sentido, também é uma prática representativa de um determinado lugar na escola, nesse caso, o feminino. Como problematiza o trabalho de Santos (2008), ao trazer a fala de uma professora que, por meio de risadas e piadas, justificou que os meninos não faziam as aulas de dança por vontade dos pais. $O$ consentimento por parte da docente era uma garantia perante pais e colegas de que "a constituição da heterossexualidade a partir da inibição à participação em atividades que são consideradas femininas" (SANTOS, 2008, p. 87) estava sendo consentida e, portanto, reiterada. Havia uma compreensão por parte da professora de que a prática da dança pode produzir sexualidades "desviantes" para o sexo biológico masculino, o que justifica a postura de silenciamento perante a não realização dessa prática corporal por parte dos meninos. Nesse sentido, a constituição desses corpos é apresentada nos trabalhos como uma sexualidade heterossexual, subordinada a uma lógica generificada de ser feminina e ser masculino. A prática social que constitui essa lógica normativa é a própria prática pedagógica.

\footnotetext{
O gênero é introjetado no sentido de normalizar condutas, a fim de parecer próprio de uma natureza. À medida que este controle vai sendo regulado pelo próprio sujeito, o grau de coerção externa diminui. Portanto, as normas não são apenas interiorizadas ou internalizadas, mas inscritas, incorporadas, e produzem corpos que significam essa norma sobre o corpo e através dele (SILVESTRIN, 2013, p.74).
}

O "não-dito", nesse sentido, ensina que há uma moral sexual do corpo social regulando as relações escolares. Esses ensinamentos invadem outros espaços escolares, entra "nas práticas escolares e nas vivências coletivas das brincadeiras das crianças, promovendo uma única forma de sexualidade, aquela que legitima e valoriza masculinidades e feminilidades heterossexuais" (WENETZ, 2012, p.42). Ensinamentos que continuam a ser operacionalizados fora das aulas de Educação Física, como apresenta Wenetz ao observar essa lógica presente 
nas brincadeiras realizadas durante 0 recreio. A autora mostra que a heterossexualidade se institui como regra a partir do momento em que "[...] Joãopoderia brincar de qualquer coisa, desde que sempre representasse o papel de homem. Ele poderia ser quem quisesse, desde que a heterossexualidade fosse mantida" (WENETZ, 2005, p. 154), já que "um menino com interesses que seriam considerados de meninas é visto como homossexual" (WENETZ, 2005, p. 164).

Wenetz (2012) discute queessa lógica segue uma "[...] sobreposição entre gênero e heterossexualidade, que serve para distanciar a homossexualidade da masculinidade" (WENETZ, 2012, p. 150), e, com isso, reiterar o lugar da sexualidade na escola. O modo como o gênero é incorporado nas brincadeiras e como ele opera nesses contextos se dá de diferentes maneiras, em que a autora apresenta como processos de generificação. Esse processo permite "discutir como, a quem e de que maneira os significados culturais de feminilidade e masculinidade são atribuídos nas brincadeiras que realizam" (WENETZ, 2013, p. 199). É possível dizer, portanto, que a discussão de gênero nos trabalhos visa apresentar o quanto a prática pedagógica vem escolarizando a sexualidade dos corpos e problematizando o quanto os atributos culturais são acionados para reforçar uma suposta essência biológica heterossexual. Estão dizendo, sobretudo, que a sexualidadeé produzida socialmente.

A estratégia do silêncio também é apresentada pela omissão de determinados termos e saberesque constituem osdocumentos oficiais que regem o currículo escolar na Educação Física. Os trabalhos deixam evidente que "[...] aquilo que não se diz é tão ou mais significativo do que aquilo que se diz, porque demonstra o que é e o que não é relevante para estar ali, e assim o aprendizado se dá através do currículo oculto" (SILVESTRIN, 2013, p. 52). Com base nessa ideia, ou melhor, na falta de discussão sobre o tema em documentos oficiais, os trabalhos mostram que um dos efeitos desse "não-dito" é pensar o corpo constituído em um determinado lugar, o da heterossexualidade.

Esse lugar, marcado, em sua maior parte, pelo silêncio, é apresentado nos trabalhos como um espaço de disputa e conflitos. Segundo os pesquisadores, a produção dos discursos que constituem a "falta de conhecimento" sobre sexualidade nos documentos pode ser analisada pelos diversos meios utilizados para tratar o tema na escola, que ora se apresentamem ações pontuais, como participação em palestras, e em políticas de governo descontínuas para tratar o tema no processo de formação (SANTOS, 2008; SILVESTRIN, 2013), ora expondo que os maiores investimentos por parte do governo se dão pelo Ministério da Saúde e visam educar os corpos escolares, por meio da prescrição da "saúde como reguladora das práticas sexuais" e a partir de uma determinada idade (SFAIR, 2012, p. 18; SILVESTRIN, 2013). Ou seja, ao analisarem os documentos e as práticas pedagógicas, os trabalhos mostram 0 quanto 0 desconhecimento sobre o tema fundamenta o silêncio. Issoé possível identificar nos trabalhos desenvolvidos por Santos (2008) e Silvestrin (2013), quando as(os) docentes entrevistadas(os) justificam a falta de conhecimento sobre o tema em virtude da formação, em "que as disciplinas obrigatórias do currículo não prepararam para essa realidade" (SILVESTRIN, 2013, p. 92). A falta de discussão sobre o tema no processo de formação soma-se às demandas produzidas, dentro e fora das aulas de Educação Física, em que onão ver, não agir, dá lugar a uma determinada lógica, a heterossexual (SANTOS, 2008; SFAIR, 2012; SILVESTRIN, 2013; WENETZ, 2012).

Ao mesmo tempo, essa mesma falta de conhecimento sobre o tema, que justifica 0 silêncio pedagógico, também anuncia a Educação Física como uma das disciplinas curriculares 
mais próximas do diálogo entre o corpo e a sexualidade, por entender que "o corpo é "peçachave' na articulação dos conteúdos da cultura corporal com os conteúdos da Orientação Sexual" (SANTOS, 2009, p. 86). Para sustentar esse argumento, Santos (2009) vale-se dos PCN (1998) para justificar que o documento oferece contribuições teóricas para a(0) profissional trabalhar com o tema nas aulas de Educação Física. Ideia que encontra resistência em outro trabalho, por questionar o documento como instrumento pedagógico, ao trazer que "[...] a visão de gênero e sexualidade (sob perspectivas de um determinismo biológico e de saúde pública) tal qual foram propostos pelos PCN, não possibilitam uma forma mais crítica de incorporá-los aos conteúdos da disciplina" (SILVESTRIN, 2013, p. 25). Nesse sentido, é possível identificar que há conflitos sobre como o tema deve ser trabalhado na escola, todavia, há também consenso em perceber que há investimentos por parte do governo federal, por meio da publicação dos PCN, em trazer a Educação Física como um lugar para educar os corpos escolares (SANTOS, 2009; SILVESTRIN, 2013).

De modo geral, os trabalhos mostram que a falta de conhecimento sobre o tema por parte das(os) docentes, expresso pelo silêncio, produz o efeito mais potente desse processo de escolarização, o consentimento. O "não-dito" torna-se uma prática pedagógica. Mostram, ainda, que a Educação Física ocupa um lugar de fala no campo pedagógicoe, portanto, um lugar nesse processo de escolarizar os corpos escolares. Nesse sentido, a ignorância é um efeito e não uma ausência de conhecimento, como problematizado por EveSedgwick (2007), ao dizer que a invisibilidade que alguns saberes assumem perante outros traz a responsabilidade para quem (re)produz tal lógica. Ao descrever que "[...] a escola nega a sexualidade, provavelmente porque ignora", Santos (2008, p. 87) evidencia o quanto o discurso da ignorância produz a discussão da sexualidade no contexto escolar. Os trabalhos mostram, portanto, que o silêncio, justificado pelo desconhecimento sobre o tema, é uma estratégia eficiente para educar os corpos escolares, sendo o reforço e a reiteração dessa lógica heterossexual uma disciplina a parte no currículo escolar.

\section{O QUE O SILÊNCIO ENSINA NA EDUCAÇÃO FÍSICA?}

As pesquisas realizadas nos programas de pós-graduação em Educação Física problematizame denunciam o quanto o silêncio docente organiza um determinado tipo de ordenamento "pedagógico", ao consentir com a naturalização de uma lógicaheterossexual, ora operacionalizada na invisibilidade e/ou repulsa homossexual, ora projetada na inferioridade atribuída a o feminino. $O$ silêncio ensina! Ensina a conter, a controlar e a disciplinar o corpo para produzir modos "adequados" de feminilidade e de masculinidade na escola. Ensina, sobretudo, a manter a "ordem"!O silêncio diz, sem dizer, que o sexo biológico é o único acesso para produzir uma sexualidade "normal e saudável".

Ao mesmo tempo, dizer também pode produzir silêncios. Como identificado em uma entrevista realizada com uma professora, ao comentar sobre os conflitos produzidos durante uma das aulas de Educação Física, em virtude dos contatos corporais:

[...] qualquer evento que fizesse com que eles e que tivessem que ficar juntos, se ajudar, eles diziam 'não coloca a mão que isso é coisa de viado!' (risos). Terrível, né? [...] eu dizia que não é o fato de você tocar no seu amigo que você vai tá fazendo um gesto de homossexual (SANTOS, 2008, p. 103). 
Ou seja, ao dizer para ficarem despreocupados, pois o toque não torna ninguém homossexual, a professora diz, sem dizer, que há um corpo "normal" materializado em sua fala e que ele não se produz no social, mas no biológico. Ensina, sobretudo, que a materialidade do corpo se dá em uma relação direta entre pênis e masculinidade, vagina e feminilidade. $E$, nesse sentido, ficamos questionando o quanto, ao dizer, ainda é possível não dizer sobre as sexualidades.

O silenciamento é apresentado nos trabalhos como um exercício pedagógico que exige esforços corporais de repetição e regularidade de estudantes e docentes. Isto é, educar o corpo para a heterossexualidade exige, literalmente, suor e esforços coletivos. Suor, no sentido de exercitar cotidianamente a linguagemem que aquele corpo precisa estar para assumir uma determinada prática corporal. Esforços coletivos, por entender que os controles e as regulações se dão pelos lugares de fala e de saberes que conquistaram o status de "verdade" naquele contexto escolar.

Esse processo de educar os corpos escolares é fortemente anunciado nos trabalhos pelo "não-dito". Trata-se de uma prática pedagógica que visa invisibilizar os conflitos e as singularidades produzidas nas práticas corporais, de forma a "anular o outro, em lugar de reconhecê-Io" (SARTI, 2010, p. 78). O silêncio ensina, ainda, que há um processo de escolarização da sexualidade sendo produzido dentro e fora das aulas de Educação Física. Processo esse constituído fundamentalmente por conhecimentos anátomo-fisiológicos, que trazem a heterossexualidade como a "verdade" sobre a sexualidade.

Nesse sentido, é possível identificar que a mesma lógica que produz o corpo normal e anormal é a lógica utilizada para pensar o gênero. Ao trazerem o gênero sendo produzido socialmente a partir de uma essência biológica, os trabalhos ampliam a ideia da construção social, masse pautam em um biológico inquestionável. Isso pode ser percebido quando os trabalhos se valem da lógica heteronormativa, estável, para denunciar os modos como 0 feminino e o masculino estão sendo (re) produzidos e, portanto, escolarizados nas aulas de Educação Física. O peso atribuído aos discursos que constituem "certas existências como 'anormais"', ao mesmo tempo, contribui para estabelecer "[...] modelos de suposta coerência entre o sexo biológico e gênero cultural como marco de normalidade e saúde" (BENTO; PELÚCIO, 2012, p. 570). Homogeneizar a produção social, cultural e simbólica do feminino e do masculino, portanto, possibilita denunciar as diversas formas de violência vivenciadas na escola,mas, ao mesmo tempo, traz a sexualidade subsumida a uma essência biológica binária, conferindo, sobretudo, cientificidade a essa lógica.

Por fim, é possível identificar que osilêncio das(os) docentes representa a crítica mais expressiva dos trabalhos sobre a prática pedagógica. Para justificar a ausência de discussão sobre as questões que envolvem a sexualidade na escola, as(os) docentes dizem que durante a formação tiveram disciplinas que trataram sobre as questões biológicas e fisiológicas que constituem o corpo, contudo, não se sentem preparadas(os) para lidar com o tema no contexto escolar (SANTOS, 2008; SFAIR, 2012; SILVESTRIN, 2013). Nesse sentido, o "não-dito" apresenta-se como um meio de educar, em virtude da falta de reconhecimento de saberes sociais e culturais que envolvem o tema. Falta que se traduz no inexpressivo investimento acadêmico, na falta de políticas públicas e na ausência de discussão sobre a sexualidade no processo de formação docente. Portanto,os trabalhos dizem, sobretudo, que a falta é a estratégia mais eficiente para escolarizar a sexualidade na Educação Física. 


\section{REFERÊNCIAS}

ALTMANN, Helena. Rompendo fronteiras de gênero: Marias [e] homens da Educação Física. 1998. 110 f. Dissertação (Mestrado em Educação) - Faculdade de Educação, Universidade Federal de Minas Gerais, Belo Horizonte, 1998.

ALTMANN, Helena. Orientação sexual nos Parâmetros Curriculares Nacionais. Revista Estudos Feministas, v, 9, n 2, p. 575-585, 2001.

ALTMANN, Helena. Sobre a educação sexual como um problema escolar. Linhas, v. 7, p. 3-17, 2006.

BENTO, Berenice; PELÚCIO, Larissa. Despatologização do gênero: a politização das identidades abjetas. Revista Estudos Feministas,v. 20, n. 2, p. 559-568, maio/ago. 2012.

BRASIL. Secretaria de Educação Fundamental. Parâmetros Curriculares Nacionais: terceiro e quarto ciclos: apresentação dos temas transversais. Brasília, 1998.

BRASIL. Secretaria de Educação Fundamental. Parâmetros Curriculares Nacionais: Educação Física. Brasília, 1998.

BRASIL. Ministério da Saúde. Departamento de DST, Aids e Hepatites virais. Boletim Epidemiológico AIDS e DST 2011. Disponível em:<http://www.aids.gov.br/sites/default/files/ anexos/publicacao/2011/50652/boletim aids_2011 final m pdf 26659.pdf >. Acesso em: 5 fev. 2013.

BRITZMAN, Deborah. Curiosidade, sexualidade e currículo. In: LOURO, Guacira Lopes (org.). 0 corpo educado: pedagogias da sexualidade. 2 ed. Belo Horizonte: Autêntica, 2001. p. 83-112.

BUTLER, Judith. Excitable speech: a politics of the performative. New York: Routledge, 1997.

BUTLER, Judith. Gender trouble:feminism and the subversion of identity. New York: Routledge, 1999.

CASTELLANI FILHO, Lino. Educação Física no Brasil: a história que não se conta. Campinas, SP: Papirus, 1988.

CASTRO, Edgardo. Vocabulário de Foucault:um percurso pelos seus temas, conceitos e autores. Tradução Ingrid Müller Xavier. Belo Horizonte: Autêntica, 2009.

CÉSAR, Maria Rita de Assis. Gênero e Sexualidade na escola: notas para uma 'epistemologia'. Curitiba. Educar em Revista, v. 35, p. 37-51, 2009.

COSTA, Jurandir Freire. Ordem médica e norma familiar. 5.ed. Rio de Janeiro:Graal, 2004.

DORNELLES, Priscila Gomes. Distintos destinos? A separação entre meninos e meninas na educação física escolar na perspectiva de gênero. 2007. 156 f. Dissertação (Mestrado em Educação) - Faculdade de Educação. Programa de Pós-Graduação em Educação, Porto Alegre, 2007.

DORNELLES, Priscila Gomes. A (hetero)normalização dos corpos em práticas pedagógicas da Educação Física escolar.2013. 193 f.Tese (Doutorado em Educação) - Faculdade de Educação. Programa de Pós-Graduação em Educação, Porto Alegre, 2013a. 
DORNELLES, Priscila Gomes. Gênero e sexualidade na Educação Física escolar: notas sobre a normalização dos corpos no interior baiano. In: DORNELLES, P. G; WENETZ, Ileana; SCHWENGBER, Maria Simone Vione (Orgs.). Educação Física e gênero: desafios educacionais. ljuí: Ed. Unijuí, 2013b. p. 215-238.

FOUCAULT, Michel.A arqueologia do saber. 7. ed. Tradução Luiz Felipe Baeta Neves. Rio de Janeiro: Forense Universitária, 2007.

FOUCAULT, Michel.História da sexualidade I: a vontade de saber. 20. ed. Tradução de Maria Tereza da Costa Albuquerque e Guilhon Albuquerque. São Paulo: Graal, 2010.

FOUCAULT, Michel.A ordem do discurso: aula inaugural no Collège de France, pronunciada em 2 de dezembro de 1970. Tradução de Laura Fraga de A. Sampaio. 22. ed. São Paulo:Loyola, 2012.

FRAGA, Alex Branco. Exercício da informação:governo dos corpos no mercado da vida ativa. Campinas,SP: Autores Associados, 2006.

GOELLNER, Silvana. Bela, maternal e feminina: imagens da mulher: Revista Educação Física. ljuí: Unijuí, 2003.

GOELLNER, Silvana. A produção de corpos hígidos: atividade física, saúde e nacionalismo no Brasil no início do século 20. In: GRANDO, BeleniSaléte. (Org). Corpo, educação e cultura: práticas sociais e maneiras de ser. ljuí:Unijuí, 2009. p. 75-94.

GÓIS JUNIOR, Edivaldo; LOVISOLO, Hugo. Descontinuidades e continuidades do movimento higienista no Brasil no século XX. Revista Brasileira de Ciências do Esporte, v. 25, n. 3, p. 41-54, set.2003.

GOMES Maria Rebeca Otero; VIEIRA, Nadjanara. Saúde e Prevenção nas Escolas: promovendo a educação em sexualidade no Brasil. Revista TempusAct em Saúde Coletiva,v. 4, n. 2, p. 145-157,2010.

HÉBRARD, Jean. A escolarização dos saberes elementares na época moderna. Teoria \& Educação, n. 2, p. 65-109, 1990.

LEÃO, Andreza Marques de Castro; RIBEIRO, Paulo Rennes Marçal. Educação sexual e a formação contínua de professores: uma estratégia para a prática pedagógica em sala de aula. A educação sexual na escola. ELO 19 - Revista do Centro de Formação Francisco de Holanda, v. 19, p. 55-61, jun.2012.

LINHALES, MeilyAssbú. A escola e o esporte:uma história de práticas culturais. São Paulo: Cortez, 2009.

LINO, Castellani Filho. Educação Física no Brasil: a história que não se conta. 14. ed. Campinas,SP: Papirus, 2007.

LOURO, Guacira Lopes. Gênero, sexualidade e educação: uma perspectiva pós-estruturalista. Rio de Janeiro: Vozes, 1997.

LOURO, Guacira Lopes. Gênero e sexualidade: pedagogias contemporâneas. Pro-Posições, v.19, n. 2, p.17-23, maio/ago. 2008.

LOURO, Guacira Lopes. Heteronormatividade e homofobia. In: JUNQUEIRA, Rogério Diniz

(Org.). Diversidade sexual na educação. Brasília: MEC, UNESCO, 2009. p. 85-93. 
MELO, Victor Andrade de. Escolas e cursos de formação de professores na Educação

Física brasileira: uma compreensão histórica. 1996. 207 f. (Dissertação de Mestrado) Unicamp, Faculdade de Educação Física, Campinas, 1996.

MELLO, Luiz; AVELAR, Rezende Bruno de; MAROJA, Daniela. Por onde andam as políticas públicas para a população LGBT no Brasil.Sociedade e Estado, v.27, n. 2, p. 289-312, 2012.

MEYER, Dagmar Estermann. Gênero, sexualidade e currículo. Boletim 26:Educação para a igualdade de gênero. Salto para o futuro, v.18, p.20-30, nov.2008.

MONTEIRO, Simone. Qual prevenção?Aids, sexualidade e gênero em uma favela carioca. Rio de Janeiro: Fiocruz, 2002.

PARAÍSO, Marlucy Alves. Currículo e aprendizagem: relações de gênero e raça na escola. In:SEMINÁRIO INTERNACIONAL FAZENDO GÊNERO 7., 2006.Anais... Florianópolis: UFSCUDESC, 2006. v. 1, p. 1-8.

PINTO, Maria Cristina Domingues. Orientação sexual e educação sexual. Boletim GTPOS, n. 4, p. 1-4, jul./set. 1995.

RICH, Adriene. Compulsory heterosexuality. In: ABELOVE, H.; BARALE, M.; HALPERIN, D. (Ed.). Thelesbian and gay studies reader. New York: Routledge, 1993. p. 227-254.

ROMERO, Elaine. A Educação Física a serviço da ideologia sexista. Revista Brasileira de Ciências do Esporte, v. 15, n. 3, p. 226-234, jun. 1994.

SALIH, Sara. Judith Butler e a Teoria Queer. Tradução de Guacira Lopes Louro. Belo Horizonte: Autêntica, 2012.

SANT'ANNA, Denise Bernuzzi de.Educação Física e história. In: CARVALHO, Yara; RUBIO, Katia (Org.). Educação Física e Ciências Humanas. São Paulo: Hucitec, 2001. p. 105-115.

SCOTT, Joan. Gênero: uma categoria útil de análise histórica. Educação e Realidade, v.20, n.2, p. 71-99, jul./dez. 1995.

SEDGWICK, EveKosofsky. A epistemologia do armário. Cadernos Pagu, v. 28, p. 19-54, jan.jjun. 2007.

SILVA, Marcelo Moraes. Escola e Educação Física: maquinaria disciplinar, biopolítica e generificante. Revista Brasileira de Ciências do Esporte, v. 34, n. 1, p. 343-357, abr./jun. 2012.

SILVA, Regina Célia Pinheiro; NETO, Jorge Megid. Formação de professores e educadores para abordagem da educação sexual na escola: o que mostram as pesquisas. Revista Ciência \& Educação,v. 12, n. 2, p. 185-197, 2006.

SOARES, Carmen Lúcia. Educação Física:raízes européias e Brasil. 2.ed. Campinas: Autores Associados, 2001.

SOARES, Carmen Lúcia. Notas sobre a educação no corpo.Educar, n. 16, p. 43-60, 2000.

UNBEHAUM, Sandra; CAVASIN, Sylvia; GAVA, Thais. Gênero e sexualidade nos currículos de pedagogia. In: SEMINÁRIO INTERNACIONAL FAZENDO GÊNERO 9: Diásporas, diversidades, deslocamentos.Anais... Florianópolis: UFSC-UDESC, 2010. p. 1-10. 
VIGARELLO, George. A invenção da ginástica no século XIX: movimentos novos, corpos novos, Revista Brasileira de Ciências do Esporte, v. 25, n. 1, p. 9-20, set. 2003.

WEEKS, Jeffrey. O corpo e a sexualidade. In: LOURO, Guacira (Org.). 0 corpo educado: pedagogias da sexualidade. 2. ed. Belo Horizonte: Autêntica, 2001. p.35-82.

WENETZ, lleana. Bonecas e Barbies no contexto escolar: feminilidades em pauta? In: DORNELLES, P. G; WENETZ, I.; SCHWENGBER, M. S.V. (Org). Educação Física e gênero: desafios educacionais. ljuí: Unijuí, 2013. p. 193-214.

\section{Apoio financeiro:}

